\title{
ITENS PARA CONSTRUÇÃO DO PROTÓTIPO DE UM ROBÔ CONTROLADO POR ARDUÍNO
}

Gustavo Caetano Bernardes'; Adamis Starling da Rocha'; Monique Francine Balduino França'; Valdo

Fausto de Araujo Junior ${ }^{1}$; Antônio Manoel Batista da Silva ${ }^{1}$

Universidade de Uberaba - UNIUBE11111

gustavober59@gmail.com; antonio.manoel@uniube.br

\section{1 - Introdução}

Em uma breve análise sobre a evolução das máquinas e as aplicações de tecnologias em empresas e fábricas, observa-se uma interação entre dois campos: a mecânica e a eletrônica. Tal interação permite 0 desenvolvimento de tecnologias capazes de realizarem funções mecânicas simples, e até as mais complexas, como elevar um objeto ou realizar uma função operária. Qualquer uma dessas atividades pode ser autônoma embora dependente da eletrônica para a realização dos movimentos. Este projeto apresenta os itens para construção de um protótipo de um robô autônomo controlado por arduíno. Nessa perspectiva este trabalho visa desenvolver o planejamento do protótipo de um robô capaz de realizar as funções básicas como andar e capturar imagens e vídeos, utilizando de variados recursos e aplicando a integração da mecânica, eletrônica e programação.

\section{2 - Materiais e métodos}

O robô autônomo é projeção de funções simples que substitui a mão de obra humana, ganhando agilidade, segurança e melhorias para as empresas e fábricas. Funções simples economizam tempo quando executadas por um robô, como por exemplo a vigilância de uma produção. Para tal execução o dispositivo em questão utiliza-se de componentes como: placa Arduíno, controle analógico, câmera wireless, barramento wireless, servomotor e um chassi. A integração desses componentes permite que o usuário realize locomoção por meio de controle analógico e o envio das capturas de vídeos e imagens para dispositivos que possuem a tecnologia wireless, durante o caminho percorrido. Seguem as características dos itens que serão utilizados:

- Arduíno R3 Uno: constituído de placa de circuito impresso com o micro controlador Atmega328-Pu. A placa possuí entrada de $20 \mathrm{~V}$ e comunicação via USB;
- Câmera Wireless: com bateria recarregável, permite registrar foto e vídeos;

- Controle analógico: Controle analógico da Sparkfun confeccionado em placa de circuito impresso que contém cinco botões analógicos, um botão de reset e dois potenciômetros;

- Servo Motor: Com alimentação externa de 4,8 V, o servo-motor da TG9e é de $9 \mathrm{~g}$, e apresenta torque capaz de puxar até $1,5 \mathrm{~kg}$;

- Programação em C: permite programar o micro controlador;

- Chassis Magiciam que é uma plataforma de robô de Dagu. Possui dois motoredutores com rodas de 65 milímetros e um rodízio na traseira. As placas do chassi são em acrílico, contém furos para montagem de sensores, de controladores e para excitação do circuito;

- Barramento Wireless: placa de circuito impresso capaz de receber e enviar comandos via Wi-Fi;

\section{3- Resultados e discussão}

"A placa Arduino utiliza como programação a linguagem $C$, é bastante simples formada por dois blocos de funções que carregam outros blocos de funções (SILVEIRA, 2012, p.2)" (figura 1).

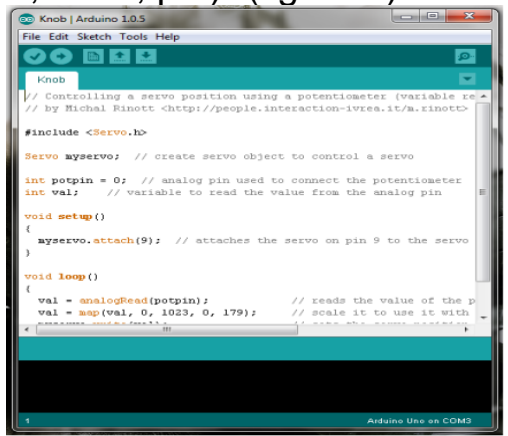

Figura 1 - Programação da placa arduino Fonte: Autores

E para realizar a programação basta conectar a placa micro controladora a um computador. A comunicação entre o computador e o micro controlador acontece 
por meio da porta COM 1 ou 3 do computador.

Para locomover a estrutura utiliza-se um chassi com rodas mecânicas com capacidade de serem controladas pelo Arduino e implementado por 2 barramentos wireless para realizar o envio de comandos também via wireless, descartando os fios e a utilização da mesa de prova para a programação.

"O Arduíno Uno R3 é uma placa de circuito impresso. $O$ seu principal componente é o micro controlador Atmega328-Pu que funciona em $20 \mathrm{MHz}$ de frequência. $O$ dispositivo possui memória flash de 32Kbs (Mcroberts, 2011, p. 22)". Além disso, é provido de uma CPU de 8-bits e contém 32 entradas, divididas em 16 PWM (modulação por largura de pulso) e 16 analógicas. A placa de circuito contém ainda uma entrada para alimentação de até 6 a 20 $V$, sendo que 0 valor recomendado se entende entre os valores 7 a $12 \mathrm{~V}$. Adicionalmente, destaca-se que o dispositivo dispõe de uma entrada USB (universal serial bus) que possibilita a programação no micro controlador. Além do mais a placa traz conectores distribuídos ao longo de sua estrutura: são entradas analógicas, digitais e terras.

A placa de circuito impresso empregada com o controle analógico é padronizada pela Sparkfun e se comunica com a placa Arduíno Uno R3 (figura 2). O controle é executado diretamente com o controle analógico, o que prescinde da mesa de teste.

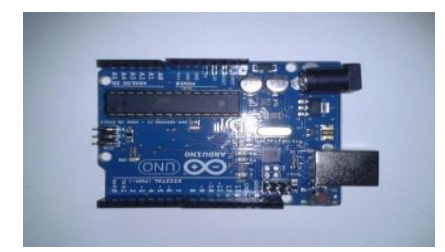

Figura 2 - Arduino R3 Uno Fonte: Autores

A referida placa constitui-se de cinco botões. Quatro deles são distribuídos na forma de cruz e o último é colocado abaixo do controle analógico. Dois potenciômetros de $10 \mathrm{k} \Omega$ compõem o controle, cujo componente serão soldados para maior precisão nos comandos de movimento

Dois servos motores (figura 3) serão usados para efetuar o controle da câmera. Um deles faz o eixo horizontal e o outro o eixo vertical. Isto possibilita o aumento do ângulo de visão da câmera.

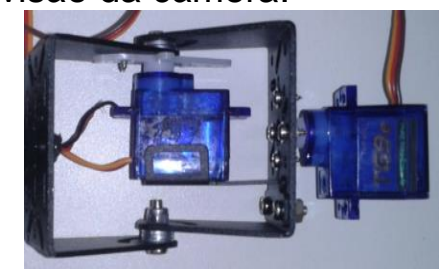

Figura 3 - Servos-motores Fonte: Autores

A webcam wireless (figura 4) possui 20 Megapixels de resolução e capacidade de até 5 metros de distância na comunicação. Tal câmara possui um botão superior para registrar fotos ou iniciar gravação de vídeo. Sua energização ocorre por meio de uma bateria recarregável de 4,8 V.

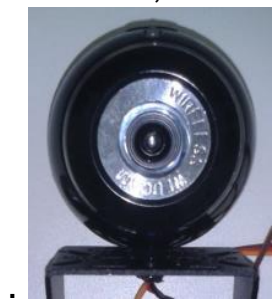

Figura 4 - Câmera Wireless Fonte: Autores

\section{4- Considerações finais}

O uso das tecnologias computacionais e mecânicas pode aprofundar o conhecimento de forma teórica e prática, envolvendo suas especificações e funcionalidades, de forma a obter um melhor emprego da estrutura e assim utilizar-se da tecnologia para a criação de um robô, totalmente controlado por Arduíno. O resultado esperado, além da aquisição do conhecimento, é validar o fato de que a robótica pode proporcionar mais comodidade e maior praticidade às atividades rotineiras.

Também é possível observar que com o emprego das tecnologias de código aberto a baixo custo, pode-se obter equipamentos com capacidade de realizar funções vitais no controle de processos e no monitoramento de vídeos, possibilitando projetar um robô autônomo utilizando materiais simples e baratos.

\section{5- Referências}

Mcroberts, M. Arduino Básico. Disponível em:<https://novatec.com.br/livros/arduino/cap itulo9788575222744.pdf>. Acesso em: 2014.

\author{
SILVEIRA, A. J. Cartilha de Programação \\ em C\# para Arduino. 1.ed, 2012.
}

